\title{
Recycling of Thermoelectric energy as a source of Electricity in the green theatre
}

\author{
Aya Mohamed Kamal EIDean Amean \\ Lecturer -Faculty of fine arts at Alexandria University
}

ayaMohamed.Kamal@alexu.edu.eg

\begin{abstract}
$\underline{\text { Abstract }}$
The economic and environmental conditions in any society are the motive for the members of this society to revolt against everything that negatively affects the environment, and it seems that recycling is the revolution against environmental pollution, as it depends on the treatment of previously consumed materials so that they are returned to their original form or re-manufactured With the aim of benefiting from it in a new way, and since thermal energy is one of the wasted wealth, the process of recycling, which is based on recovering the wasted energy from industrial processes into the atmosphere and converting it into electrical energy, and thus heat constitutes a form of energy recycling, by designing power generation equipment Electricity to extract excess and wasted thermal energy in order to maintain energy levels within the permissible environmental limits (at safe rates) to continue keeping the environment clean, in addition to reducing the risks caused by excess and emitted heat, and if we want to apply this process to theatrical architecture, we can recycle Thermal energy emitted from all the contents of the stage, such as large lights, cooling devices, and special equipment, which causes heat emissions. And re-converting it back into electrical energy, Modern architectural technology, which is concerned with keeping the environment clean, has allowed us to reduce these emissions and contribute to sustainability by creating facilities that contain all the factors of sustainability.
\end{abstract}

\section{Introduction:}

(Sustainability is linked to equality) This is what was mentioned in the Human Development Report 2011 issued by the United Nations, because the most basic rights of the peoples of the earth are social justice, increased opportunities for a better life and a green economy, and reduced carbon emissions that cause global warming.

Rationalization of energy consumption begins with attempts to abandon wasteful consumption Methods in the various life resources, and energy consumption in sustainable development standards aims to reduce total energy consumption while achieving maximum efficiency and utilization of available resources in society to create basic commodities with The value and distribution of it among the members of society in the so-called green economy to achieve an integrative relationship between the economy and the environment. 


\section{Methodology:}

An analytical survey study that depends on monitoring and analyzing the extent of technological .progress and its confirmation of the idea (recycling heat energy).

\section{Research problem:}

How some societies have been able to provide solutions that call for a clean energy revolution, which turns the planet into a source of clean energy, and therefore there will be no dark place on Earth, and to keep the planet clean and safe as God created it for us.

\section{Research Objective:}

the belief that our communities are in the face of natural disasters that we caused, due to the multiple sources of pollution represented in the gradual rise in the temperature of the atmosphere as a result of the resulting changes in the levels of thermal energy that penetrate the atmosphere and raise the temperature of the planet and ways to obtain recycled heat energy even in Entertainment places.

\section{$\underline{\text { Research procedures: }}$}

Sustainability and Equality- Rationalization of energy consumption-Sources of thermal pollution and attempts to control them-Renewable energy, clean energy

Renewable energy technology and its role in mitigating the effects of greenhouse gas emissionsThe Eden project-The Project Idea-The philosophy behind the Eden Project-The Design Strategies- The System- Management System (BMS)-Geothermal energy- Conclusion- ResultsRecommendations- Reference.

\section{Sustainability and Equality:}

saving natural resources and rationalize their consumption is a requirement for sustainable development, and the ability to preserve the elements of the ecosystem basic requirement to continue reducing carbon emissions and greenhouse gases, which increase From the rates of global 


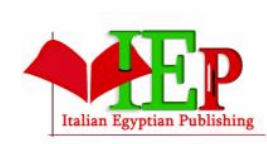

ISSN: $2735-5403$
INTERNATIONAL JOURNAL OF

ADVANCED RESEARCH ON PLANNING AND

SUSTAINABLE DEVELOPMENT

VOLUME 4, ISSUE 1, 2021, $69-85$.

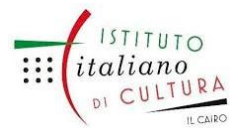

www.egyptfuture.org/ojs/

warming, which causes climate change and the extinction of one-third of known organisms on Earth.

People have the right to live in a clean and safe environment without threats of the effects of global warming that destroy the environment and cause many environmental disasters such as rising sea levels and the extinction of species of living organisms responsible for the ecological balance and the threat of Drought and desertification the consequent effects Damages to agriculture and therefore the basic food sources for humans.

\section{$\underline{\text { Rationalization of energy consumption: }}$}

The rationalization of energy consumption as one of the sustainable development standards aims to reduce the amount of primary energy, improve energy efficiency at the level of use, reduce air pollution caused by (acid rain - smog ...), and reduce the production rates of materials responsible for the formation of waste (ash ) Water pollution in rivers and oceans and soil poisoning, represented in the study of systems that control the means of energy consumption, for example, the combustion of fuel is the largest source of pollution to the atmosphere and global warming, this problem is not limited to a specific place, as the whole world is responsible for the effects of the industrial revolution, The method of modifying facilities to fit with the achievement of the principle of sustainability in terms of responsibilities and tasks in the implementation of plans to preserve the environment, Countries and institutions must abide by environmental standards as well as modern quality concepts and the extent of their observance of environmental conditions.

\section{Sources of thermal pollution and attempts to control them:}

Electricity is produced from several sources, including the combustion of fuel, which causes the emission of gases that pollute the environment and thus increase the risks of global warming. Therefore, many attempts have been made to search for ways and alternatives to generate electric power from clean energy sources (such as the sun, wind, etc.), in addition to Recycling waste electrical energy represented in the thermal energy emitted from the use of high-voltage lighting units, and scientists have developed an environmentally friendly technology called Thermo Electric generator, through which the heat emitted can be converted into electricity and thus can be exploited again, for example from Known uses Energy harvested from cars and industrial waste by coating their exhaust pipes with a thin film no more than a millionth of an inch thick that 
INTERNATIONAL JOURNAL OF

ADVANCED RESEARCH ON PLANNING AND

SUSTAINABLE DEVELOPMENT

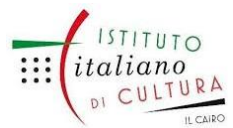

VOLUME 4, ISSUE 1, 2021, $69-85$.

www.egyptfuture.org/ojs/

absorbs heat energy, in addition to what scientists from MIT and Stanford University have developed a new technology For batteries so that they can capture waste heat and convert it into electricity in what is called Thermo galvanic, which is such a cell A thermochemical consisting of two electric columns at two different temperatures in which heat is used to provide electric energy in order to reduce pollution arising from public (social) activities and the use of modern technology to accelerate the transformation of societies into sustainable societies.

\section{Renewable energy, clean energy:}

Renewable energy is characterized by its ability to continuously exploit without this leading to the exhaustion of its source.

So it is the energy derived from traditional energy without consumption from the environment and depends on preserving the available resources to achieve sustainable development energy sources and not destroying them through the use of friendly materials and saving them for future generations. There are many forms of energy represented in heat, sound, and light, there is also mechanical energy generated by machines and chemical energy that results from chemical, electrical, hydroelectric, kinetic, radioactive, dynamic, and atomic reactions. Energy can also be converted from one form to another.

\section{Renewable energy technology and its role in mitigating the effects of greenhouse gas emissions:}

This technology aims to reduce greenhouse gas emissions from the energy system and reduce pollution, Economic development has been closely linked to the increasing use of energy in all societies need energy services to satisfy basic human needs such as (lighting - cooking - transportation etc.), and the service of the production process to sustain the development process so that the uses of energy services are safe and has low environmental effects, and this means the application of different strategies in different stages of economic development and energy services to be Environmentally safe, It should have low environmental impacts and low greenhouse gas emissions. 


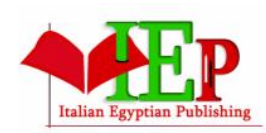

ISSN: 2735-5403

INTERNATIONAL JOURNAL OF

ADVANCED RESEARCH ON PLANNING AND

SUSTAINABLE DEVELOPMENT

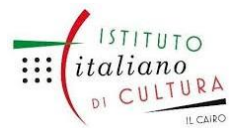

www.egyptfuture.org/ojs/
Since electric energy is produced in most cases using petroleum materials, which require not depleting it and preserving it for future generations, there was a need to adopt modern technologies that rationalize energy, not by reducing consumption, but rather by optimizing the consumption of resources, by relying on logical methods in various sectors Consumption and consequently energy conservation.

Several warnings have been issued about the concentrations of greenhouse gases in the atmosphere, which have reached another bad record, that may lead to long-term climate change, sea-level rise, changing weather, and that continuing in this trend without trying to reduce it will have devastating effects on the world Life on Earth because carbon dioxide remains in the atmosphere for hundreds of years and the oceans for much longer.

\section{The Eden project:}

Many people interested in environmental affairs in their various specialties have made many attempts to rationalize energy consumption and contribute to reducing the effects of environmental pollution and sustainability.

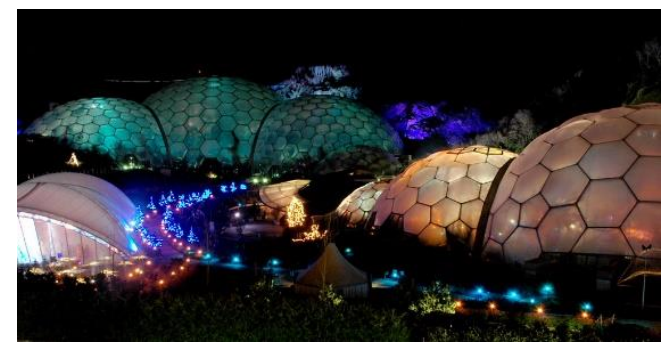




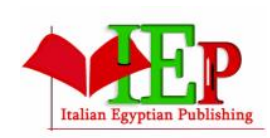

ISSN: $2735-5403$

INTERNATIONAL JOURNAL OF

ADVANCED RESEARCH ON PLANNING AND

SUSTAINABLE DEVELOPMENT

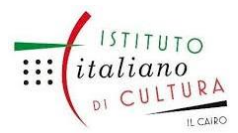

www.egyptfuture.org/ojs/

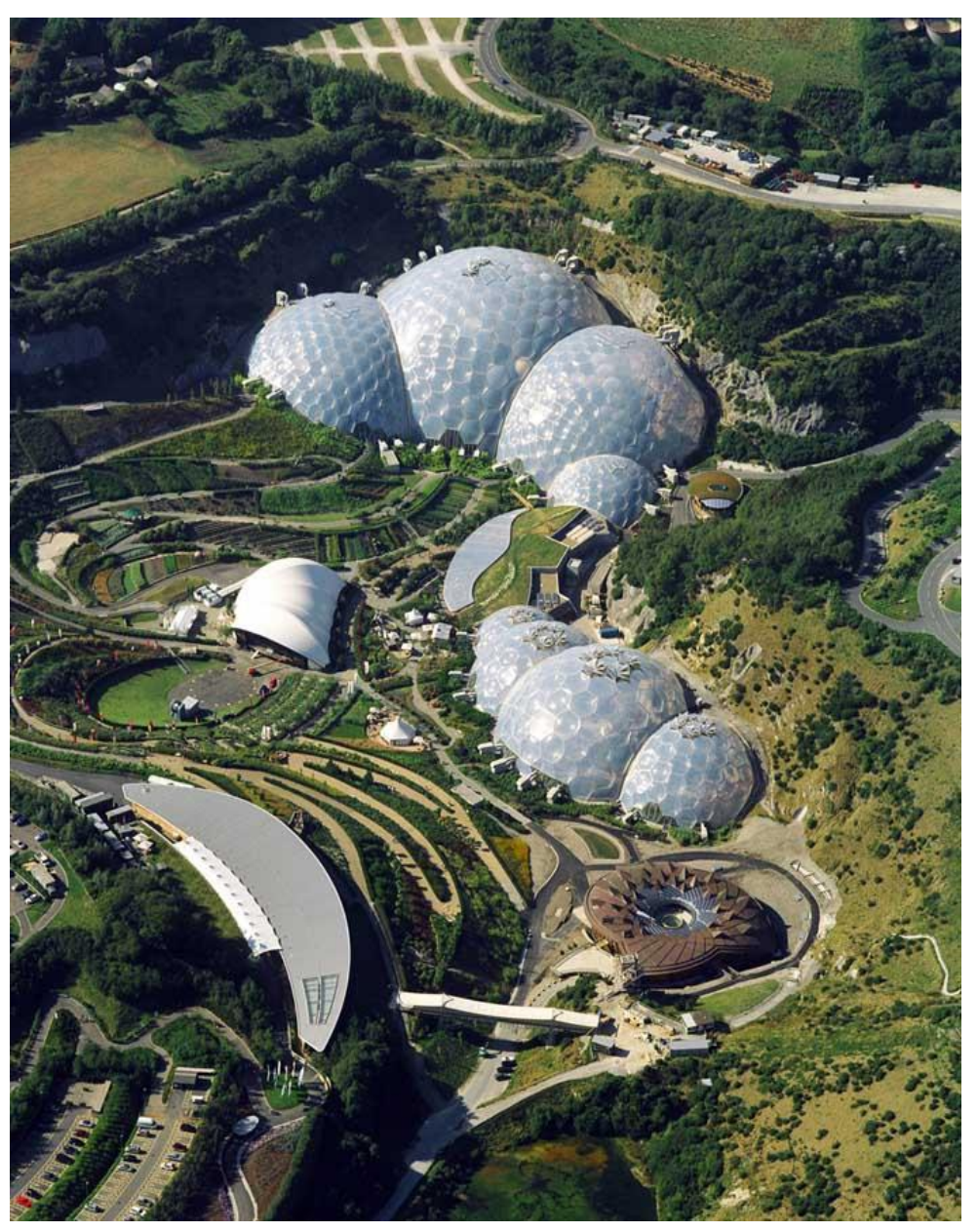

In 2001, the Eden Project was established, on the southwestern tip of England in Cornwall, it was an entertainment project that concerned with preserving the environment and achieving the principle of sustainability by building a vegetation cover that blends with the existing architectural building.

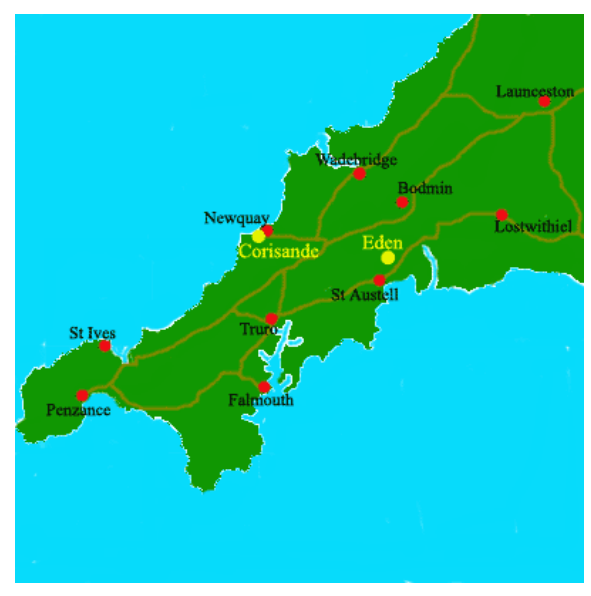

\section{The Project Idea:}

Tim Smit, an archaeologist, came up with the idea of this project to create a new life without sources of pollution, and the goal of creating this project was to create a recreational area that includes several facilities in which plants grown from around the world are displayed. It took six years to complete, and it consists of a road Zigzag leads to a group of domes surrounded by many types of plants, in addition to the use of sculptures and robots made from recycled equipment, and the structure consisting of the domes was designed from hexagonal plastic cells (layers of metal 


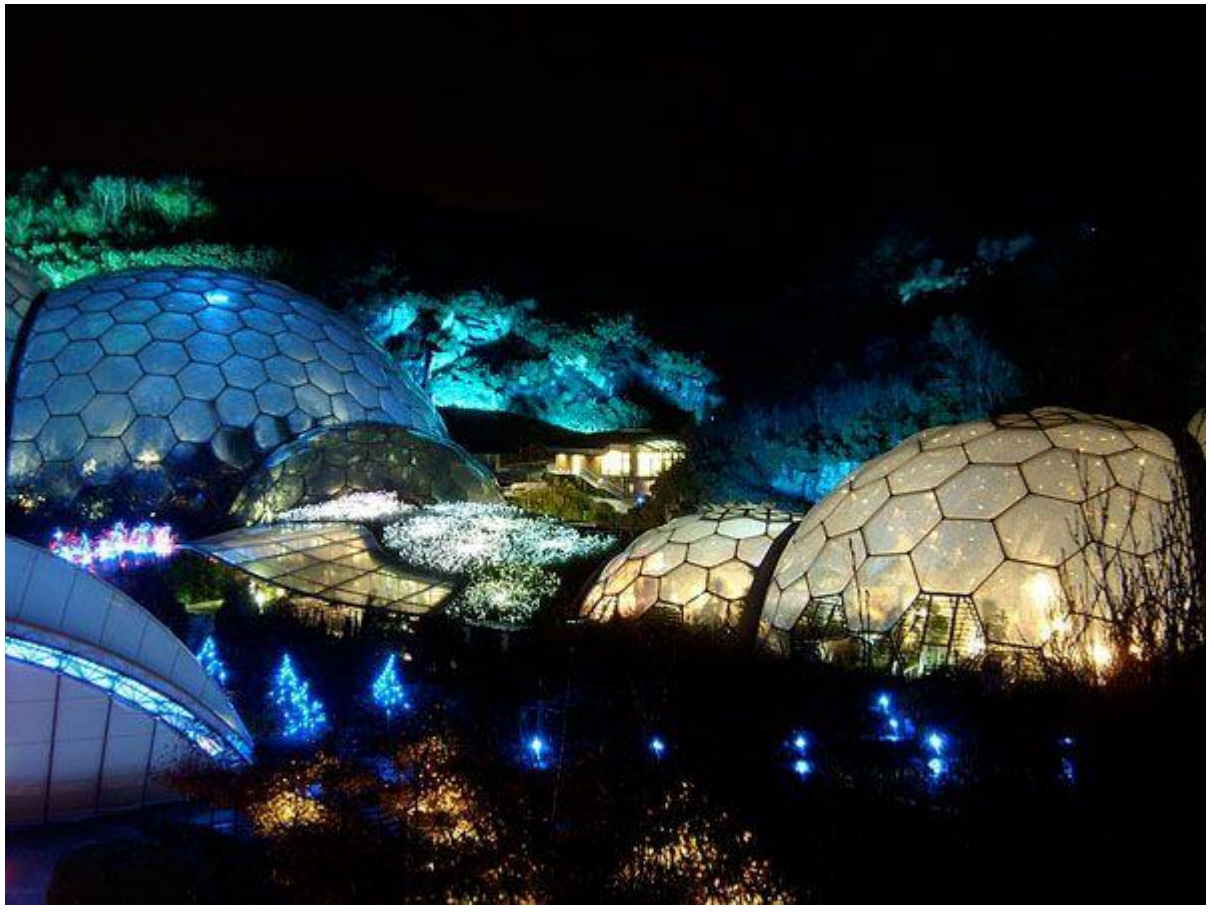

foil) suspended on steel structures to cover 2.2 hectares, The construction of the design was based on the most stable forms on the ground while providing maximum strength with minimum materials. The interior of the domes provides different growing conditions for plants, and the multiple domes of each have a different environment from the other as can also be seen on the screens installed inside, For example, a tropical dome is used for tropical plants, such as bananas, coffee, and bamboo, and they are kept at a constant tropical temperature and a high level of humidity. Medium it is slightly smaller and provides growing conditions for Mediterranean plants. There are also many other species planted in open spaces (open biomes), such as botanical gardens and flower gardens, and amenities including cafes, restaurants, and a theater.

\section{The philosophy behind the Eden Project:}

The entire Eden project philosophy was built on the idea of environmental conservation and recycling, From the purchase boxes and delivery of the plants to the design of the equipment, everything has reuse properties and even the food eaten has been specially selected with sustainability, Water from moisture is collected from all Vital areas, even that rainwater is collected underground in a specific system to be used again, and thus, two-thirds of the water used in the

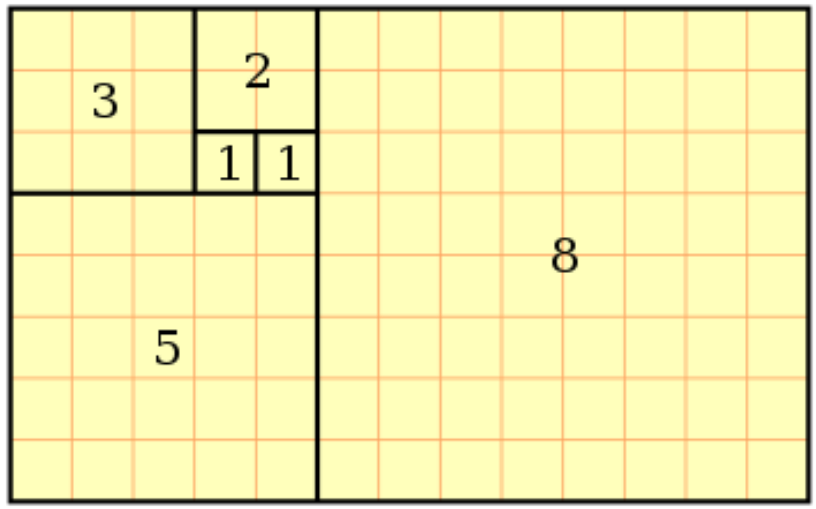
project is collected. 


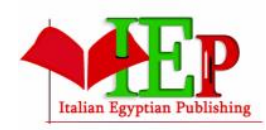

ISSN: 2735-5403

INTERNATIONAL JOURNAL OF

ADVANCED RESEARCH ON PLANNING AND

SUSTAINABLE DEVELOPMENT

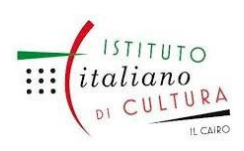

VOLUME 4, ISSUE 1, 2021, $69-85$.

www.egyptfuture.org/ojs/

As for the facilities, they are also designed from recycled materials or low-carbon products, and this project was prepared to combine recreational projects and educational projects, and the basic form of construction depends on the sequence of Fibonacci numbers as a model for everything
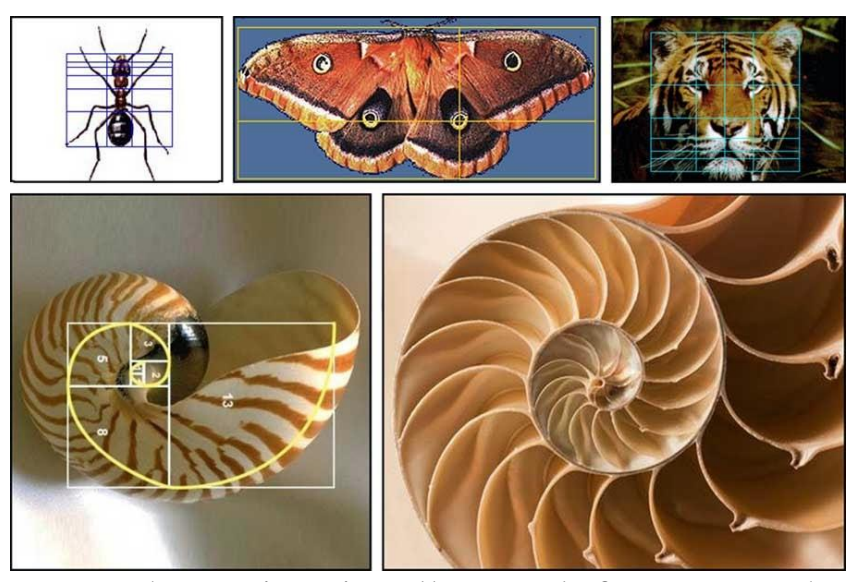

that exists in all-natural forms, such as conifers, sunflower heads, and snail shells.. 


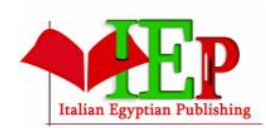

ISSN: $2735-5403$

INTERNATIONAL JOURNAL OF

ADVANCED RESEARCH ON PLANNING AND

SUSTAINABLE DEVELOPMENT

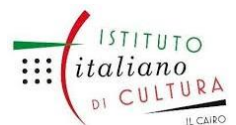

www.egyptfuture.org/ojs/

At the top of the domes, the panels collect solar energy, and the basic building materials consist of wood and have been combined with the geometric shapes of the domes, which have taken a spherical shape to collect the largest amount of sunlight, this building is characterized by the absence of columns to allow the largest amount of rays to pass through the domes.

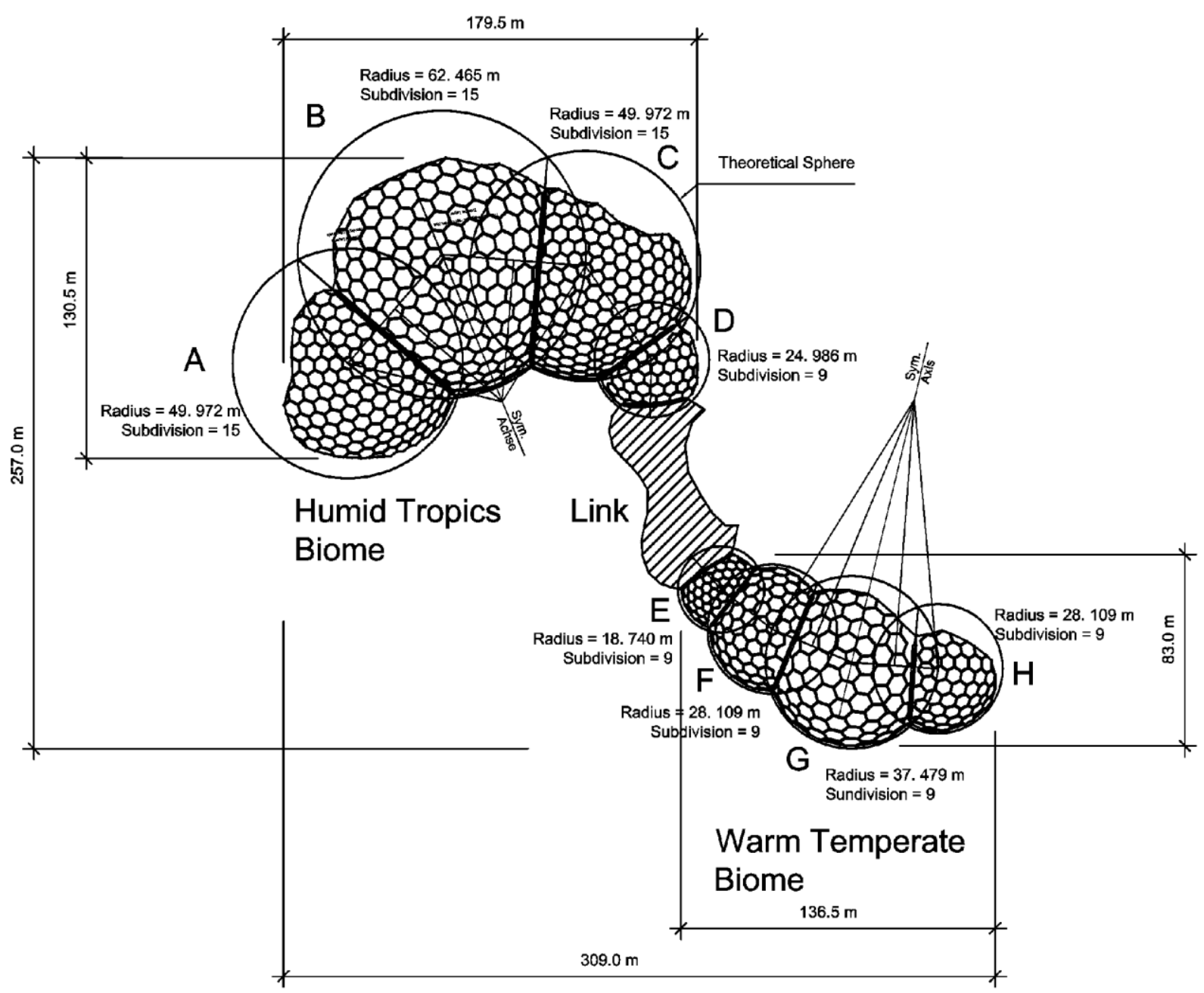

From the beginning, the mission of the Eden Project was to emphasize the vital relationship between plants, humans, and natural resources in life. This project has grown into a tourist attraction, a research and educational tool for future generations to maintain a sustainable future for all. 
INTERNATIONAL JOURNAL OF

ADVANCED RESEARCH ON PLANNING AND

SUSTAINABLE DEVELOPMENT

$\overline{\vdots: \vdots}\left(\begin{array}{c}\text { istituto } \\ \text { italiano } \\ \text { DI CULTURA }\end{array}\right.$

There are three biomes in the Eden Project: Tropical, Temperate Warm and temperate, the humidtropical region is the largest biome, with a length of more than 240 meters.

\section{The Design Strategies:}

The Eden Project uses a variety of design strategies to complement the goal of sustainability, the bubblelike geodesic structure consists of an outer shell of hexagonal pieces of steel tubes that are connected to an inner network of triangles to achieve stability.

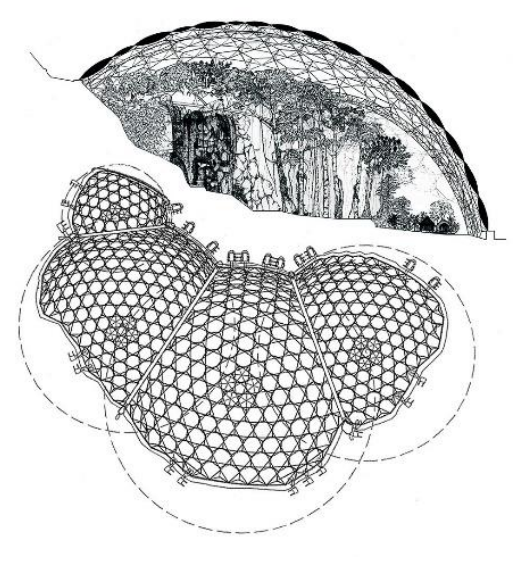

A

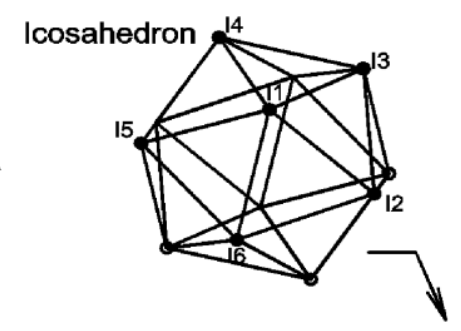

B

... concentrically positioned in a sphere

C

(I2, D1, DI-1) = "Characteristic Triangle" with Basic Hex-Net on the Surface of a Sphere
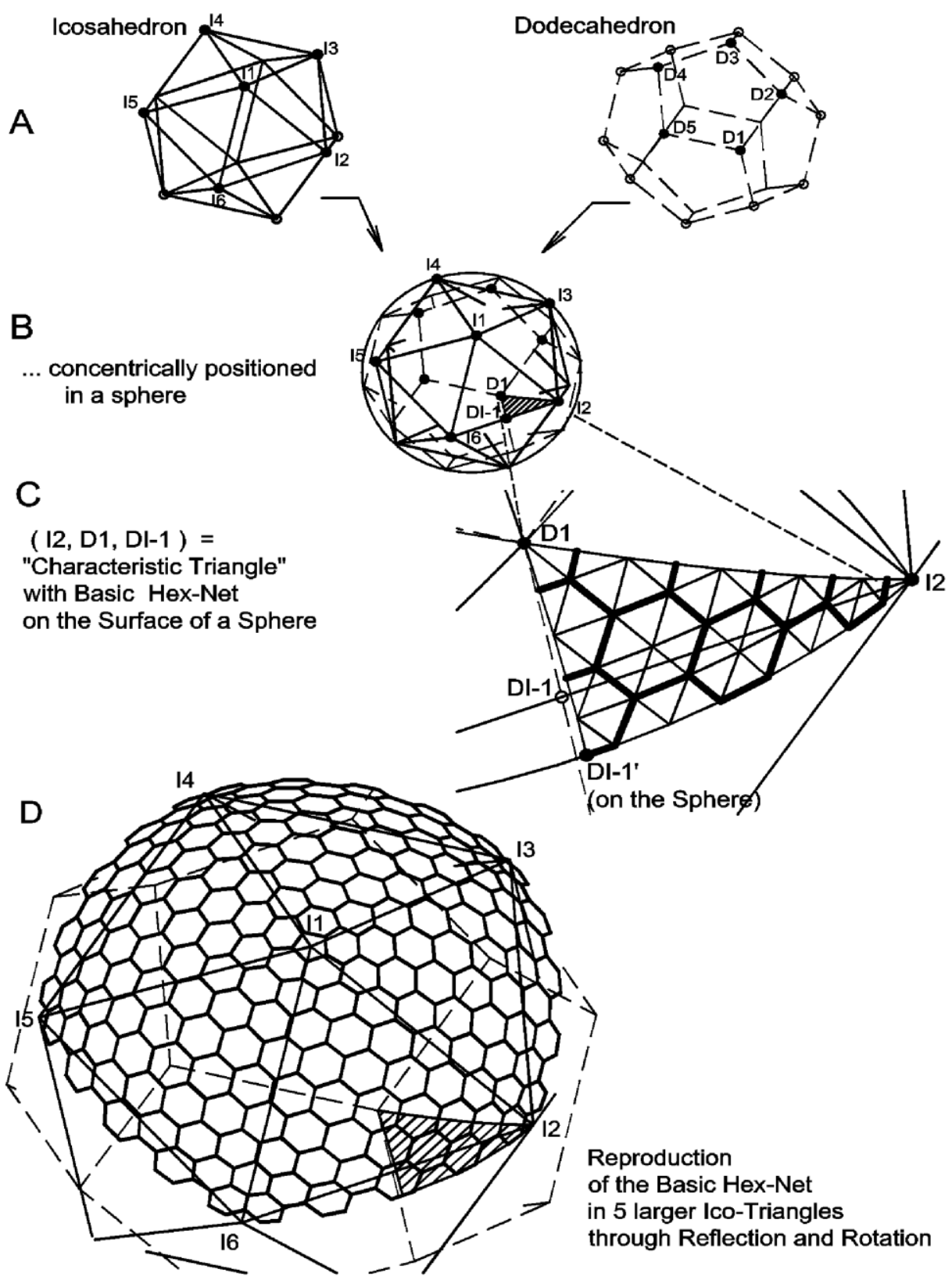


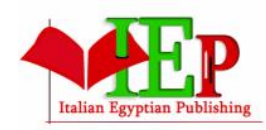

ISSN: 2735-5403

INTERNATIONAL JOURNAL OF

ADVANCED RESEARCH ON PLANNING AND

SUSTAINABLE DEVELOPMENT $\vdots: \vdots\left(\begin{array}{c}\text { istituto } \\ \text { italiano } \\ \text { di CULTURA }\end{array}\right.$

www.egyptfuture.org/ojs/

they use a computer program for thermodynamic analysis called OASYS, which helped in measuring the performance of biomes during this year's extreme weather conditions, such as hot summer afternoons or cold winter mornings, The steel structure was designed by Nicholas Grimshaw \& Partners (NGP) engineers.

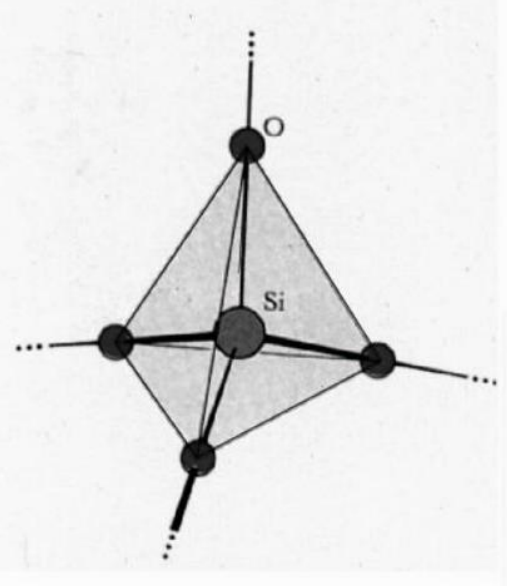

Silicate Structure of SiO4 - Tetrahedrons
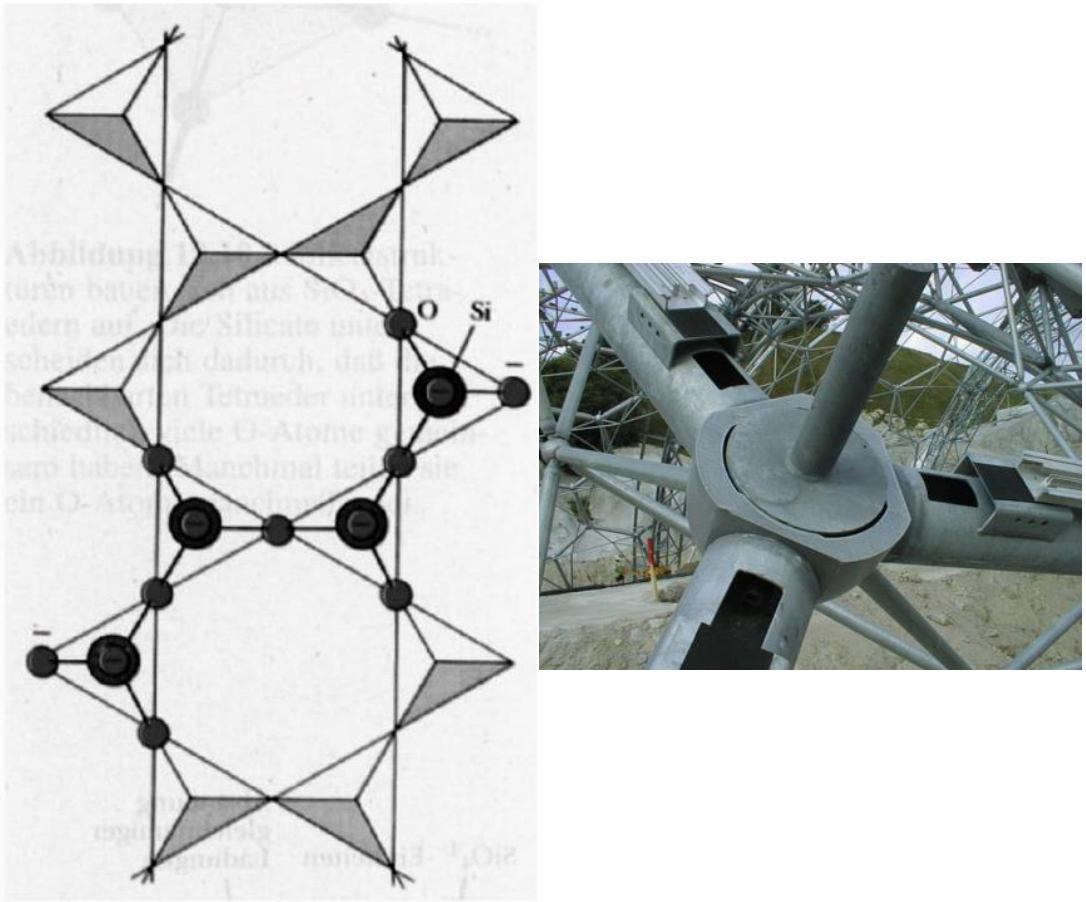

\section{The System:}

They held the tubes together by knots for complex geometries which are very light and transparent, each group consists of 4 domes $(\mathrm{ABCD})$ and the $\mathrm{B}$ dome is the largest one of all. It has a diameter of about 125 meters and a free height of approximately 55 meters

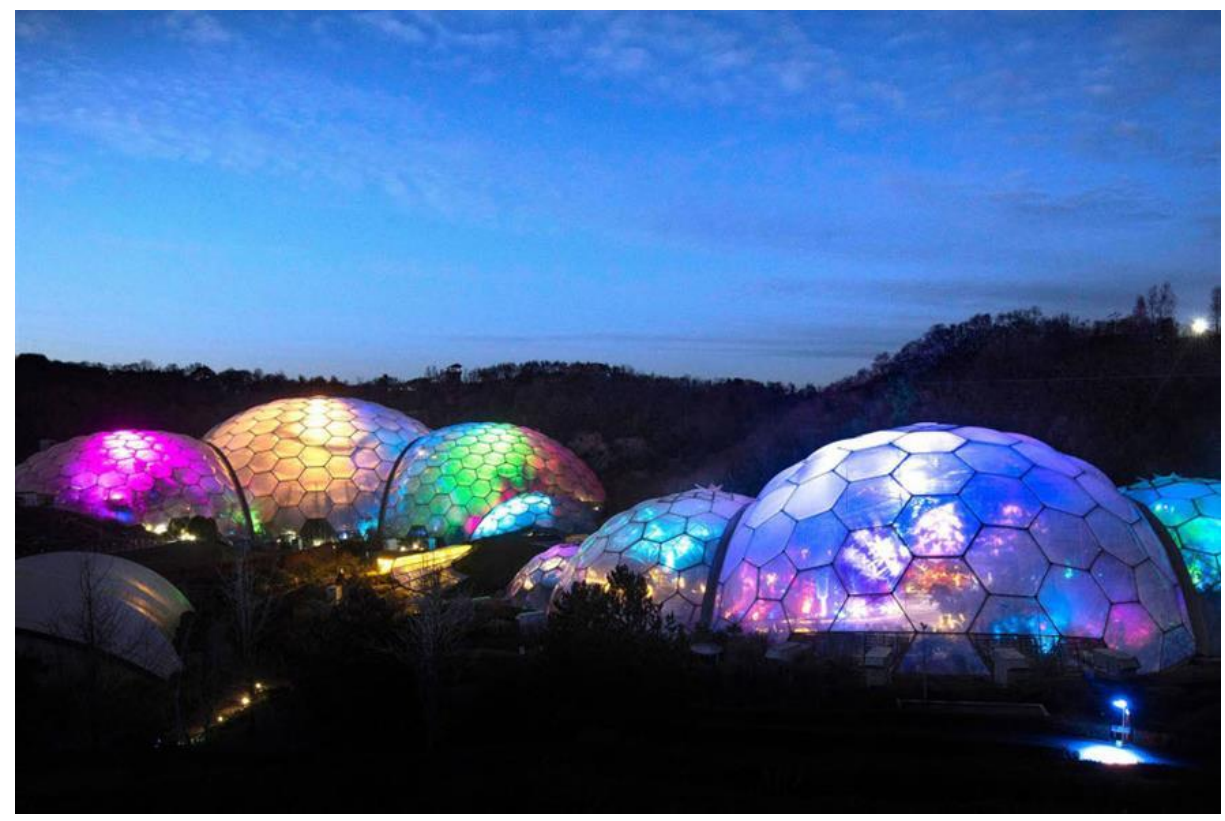




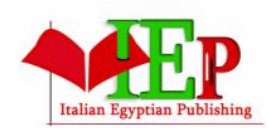

ISSN: $2735-5403$

INTERNATIONAL JOURNAL OF

ADVANCED RESEARCH ON PLANNING AND

SUSTAINABLE DEVELOPMENT

$\overline{\vdots: \vdots}\left(\begin{array}{c}\text { istituto } \\ \text { italiano } \\ \text { DI CULTURA }\end{array}\right.$

VOLUME 4, ISSUE 1, 2021, $69-85$.

www.egyptfuture.org/ojs/

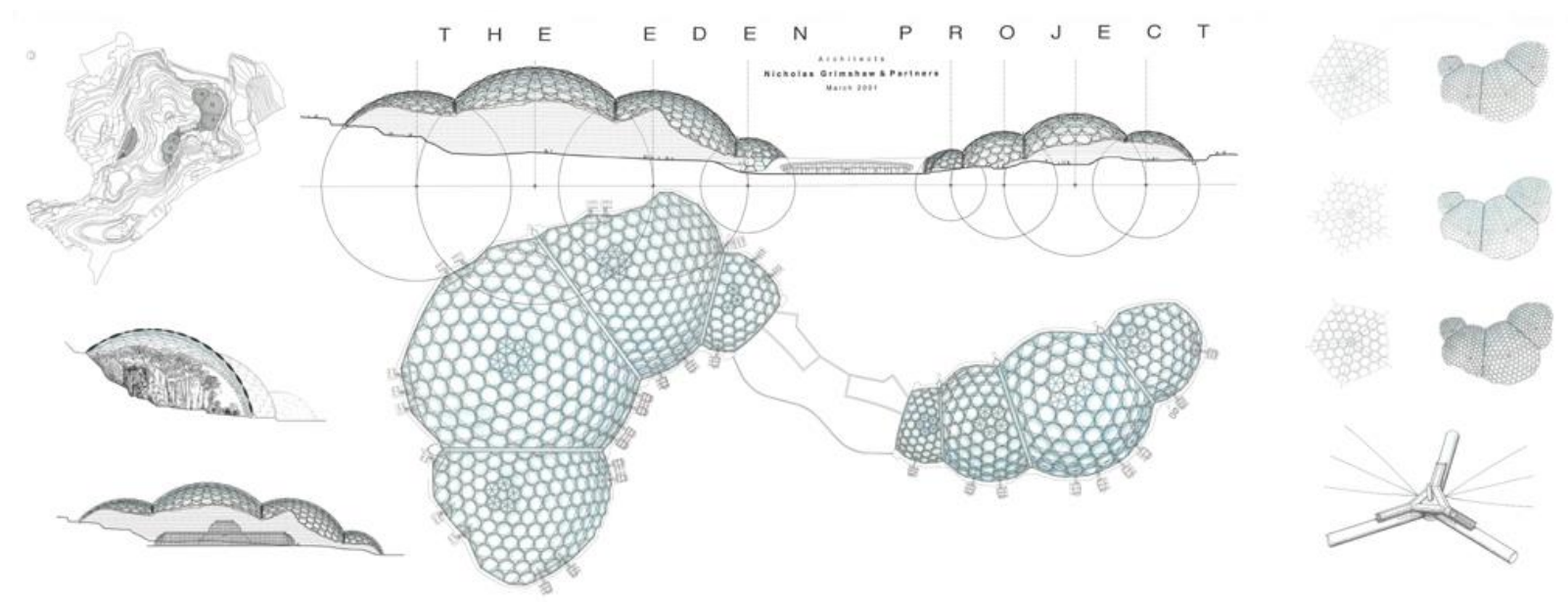

The project planning

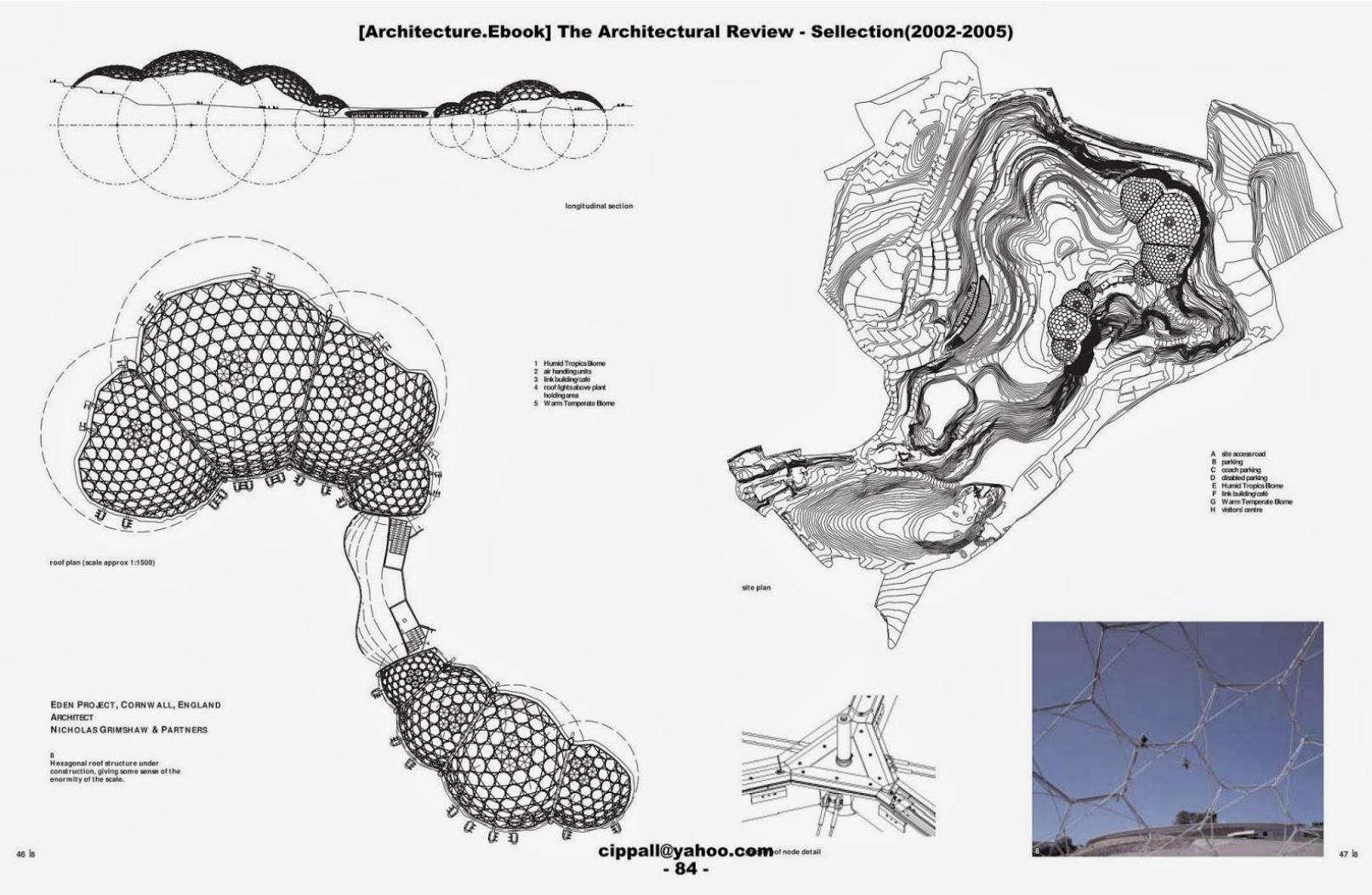

Each group consists of 4 domes (ABCD) and the $\mathrm{B}$ dome is the largest one of all. 


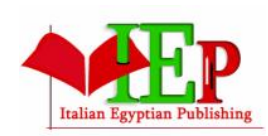

ISSN: $2735-5403$

INTERNATIONAL JOURNAL OF

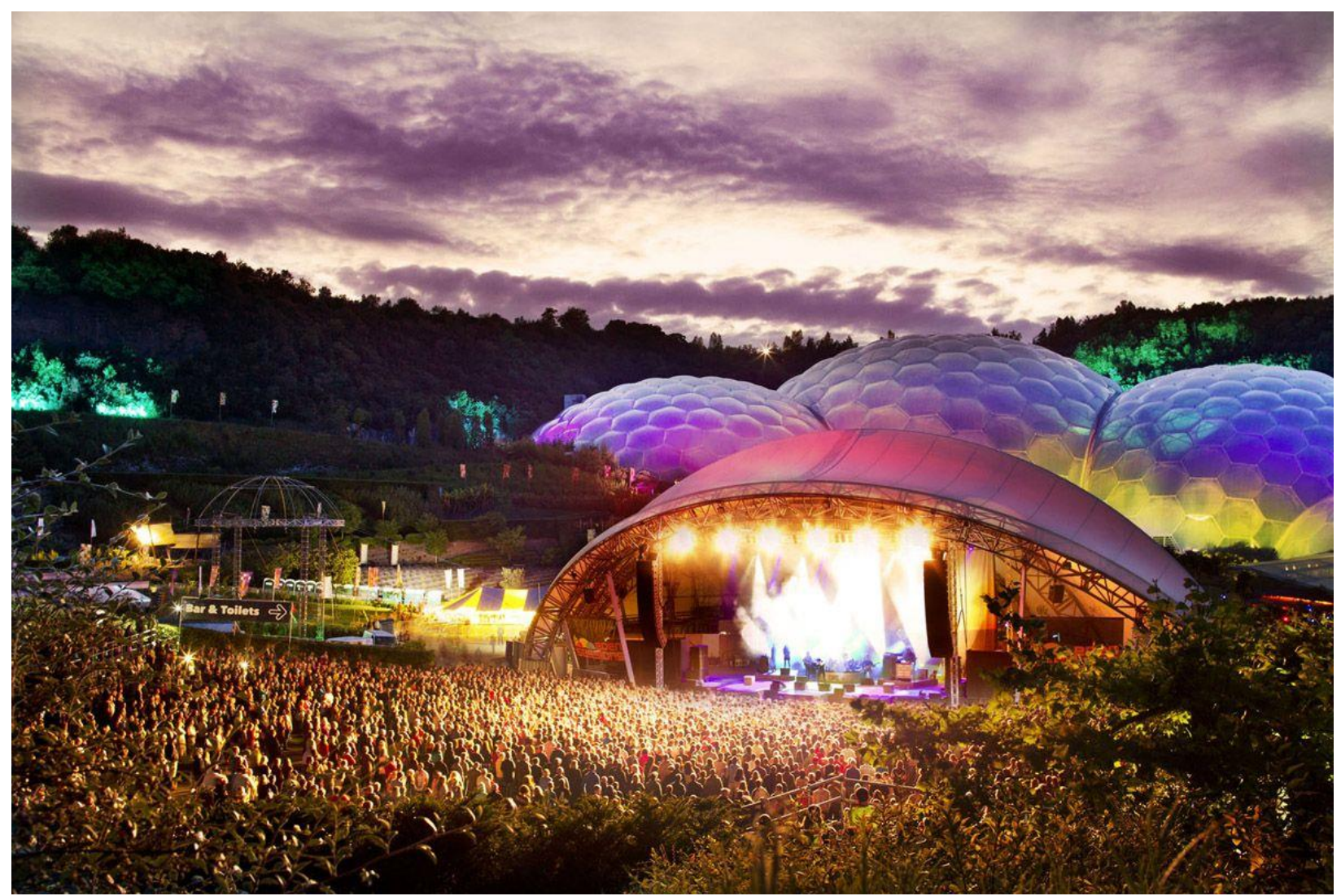

The Eden project stage

The project designers have determined its ability to reduce carbon emissions by $5 \%$ on an annual basis while reducing energy consumption to increase the excitement towards going green, not only that but to reduce energy use in the first place and thus investing in technology and design to maintain uses energy in the minimum possible to turn the building into a sustainable building. Building.

\section{Management System (BMS):}

The project buildings are controlled by integrating multiple systems into one control system 
INTERNATIONAL JOURNAL OF

\section{Geothermal energy:}

In partnership with Cornwall-based EGS Energy, a 3-4MW geothermal power plant is planned at the Eden project site to benefit thermal energy from underground granitic rocks.

The project provided the employees the opportunity to invest in a renewable energy program through polarized solar panels as part of a new program to provide free and renewable energy to the site.

\section{Conclusion:}

There is still a question about how to exploit the heat emitted from inside, can we recycle it again? Thus, it turns into electrical energy to achieve a balance between the rates of energy consumption without affecting the design of the place.

The technology of converting thermal energy into electrical energy can be exploited through the so-called Thermo Electric generator, This technology enables the conversion of thermal energy into electrical energy again, and nanotechnology has been used to reduce its size to suit many uses, in cars, for example, or even in watches where they absorb the emitted heat and converting it into electrical energy again, thus turning it into a source of renewable energy.

Thermal power generators have emerged as one of the results of new green technologies because of their various advantages. These generators convert thermal energy directly into electrical energy without containing mechanical moving parts that require maintenance. They are small in size and weight and have the ability to work at high temperatures as a source of generation Energy, so they can be run day and night. Perhaps the first application is to reuse the heat emitted by the headlights to provide electrical energy as an alternative to costly kinetic generators that run on gasoline and thus be one of the alternative energy sources. Rather, the ideas went beyond that to recover industrial waste heat and con

\section{$\underline{\text { Results: }}$}

- The uses of nanotechnology are one of the factors of transformation towards green environmental issues.

- There are many alternatives to obtaining clean energy and preserving the environment.

- The huge amount of thermal energy emitted by lighting units and equipment during theatrical performances can be exploited through devices that convert the thermal energy emitted from electrical energy sources into electrical energy again.

- Electricity in a semi-closed circuit is one of the means of energy conservation and thus achieving sustainability. 


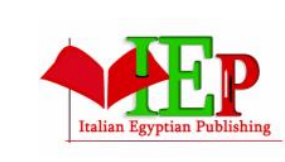

ISSN: 2735-5403
INTERNATIONAL JOURNAL OF

ADVANCED RESEARCH ON PLANNING AND

SUSTAINABLE DEVELOPMENT

VOLUME 4, ISSUE 1, 2021, $69-85$.

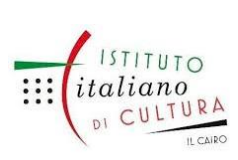

www.egyptfuture.org/ojs/

\section{$\underline{\text { Recommendations: }}$}

Based on the increasing demand for decreasing natural resources, we must find ways to protect them and provide access to clean energy, taking care that the energy we produce does not contribute to climate change, therefore, it is necessary to:

- Exploiting nanotechnology to make social transformations towards environmental and sustainability issues.

- Reducing heat emissions and recycling wasted energy flows through energy conversion (and overcoming the cooling problem as one of the problems) is one of the environmentally friendly solutions.

- Awareness of our local communities on resilience in the face of natural disasters and awareness of environmental dangers, enhancing the use of renewable energy applications and strengthening the principle of sustainable development in the human sciences.

\section{Reference:}

https://arabic.euronews.com/2015/06/26/green-house-gasses-explained https://www.france24.com https://news.un.org/ar/story/2018/11/1021831

https://land8.com/is-the-eden-project-the-birth-of-a-new-beginning/ https://www.edenproject.com/eden-story/behind-the-scenes/cutting-energy-and-carbon-at-eden http://www.syr-res.com/pictures/879510416.jpg http://www.alternative-energy-news.info/waste-heat-to-electricity/ https://www.speakerscorner.co.uk/speaker/tim-smit https://www.cornwalls.co.uk/photos/eden-project-christmas-3705.htm Nanostructured thermoelectric materials: Current research and future challenge MaterialsEngineering,TheUniversityofQueensland,StLucia,QLD4072,Australia bCentre forMicroscopyandMicroanalysis,TheUniversityofQueensland,StLucia,QLD4072,Australia Received 18July2012; accepted7October2012 Available online23December2012 .

A review of thermoelectric cooling: Materials, modeling and Applications Dongliang Zhao, Gang Tan* University of Wyoming, Department of Civil and Architectural Engineering, 1000 E. University Avenue, Dept. 3295, Laramie, WY 82071, USA Available online 12 February 2014

Waste heat energy harvesting using thermo electric generator IOSR Journal of Engineering.

(IOSRJEN) e-ISSN: 2250-3021, p-ISSN: 2278-8719 Vol. 3, Issue 7 (July. 2013), Thermoelectric Power Generation Using Waste- Heat Energy as an Alternative Green Technology Article in Recent Advances in Electrical \& Electronic Engineering · January 2010.

The structural making of the Eden Domes KLAUS KNEBEL, JAIME SANCHEZ-ALVAREZ, STEFAN ZIMMERMANN, MERO GmbH \& Co. KG, D-97084 Wurzburg, Germany. The Eden Project - making a connection John Blewitt* University of Exeter.

The Rio 20+ Conference is an acronym for the United Nations Conference on Sustainable Development to be held in Rio de Janeiro, Brazil, in June 2012. 


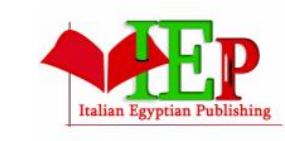

ISSN: 2735-5403
INTERNATIONAL JOURNAL OF

ADVANCED RESEARCH ON PLANNING AND

SUSTAINABLE DEVELOPMENT

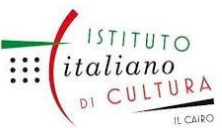

www.egyptfuture.org/ojs/

Special Report on Renewable Energy Sources and Mitigating the Effects of Climate Change - Summary Report for Policy Makers - Third Working Group of the Intergovernmental Panel on Climate Change - 2011 Intergovernmental Panel on Climate Change.

Tenth Arab Energy Conference - Abu Dhabi - United Arab Emirates December 2014 - Energy, Environment and Sustainable Development Working Pape 

ADVANCED RESEARCH ON PLANNING AND SUSTAINABLE DEVELOPMENT

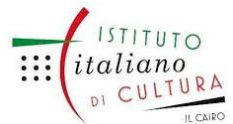

